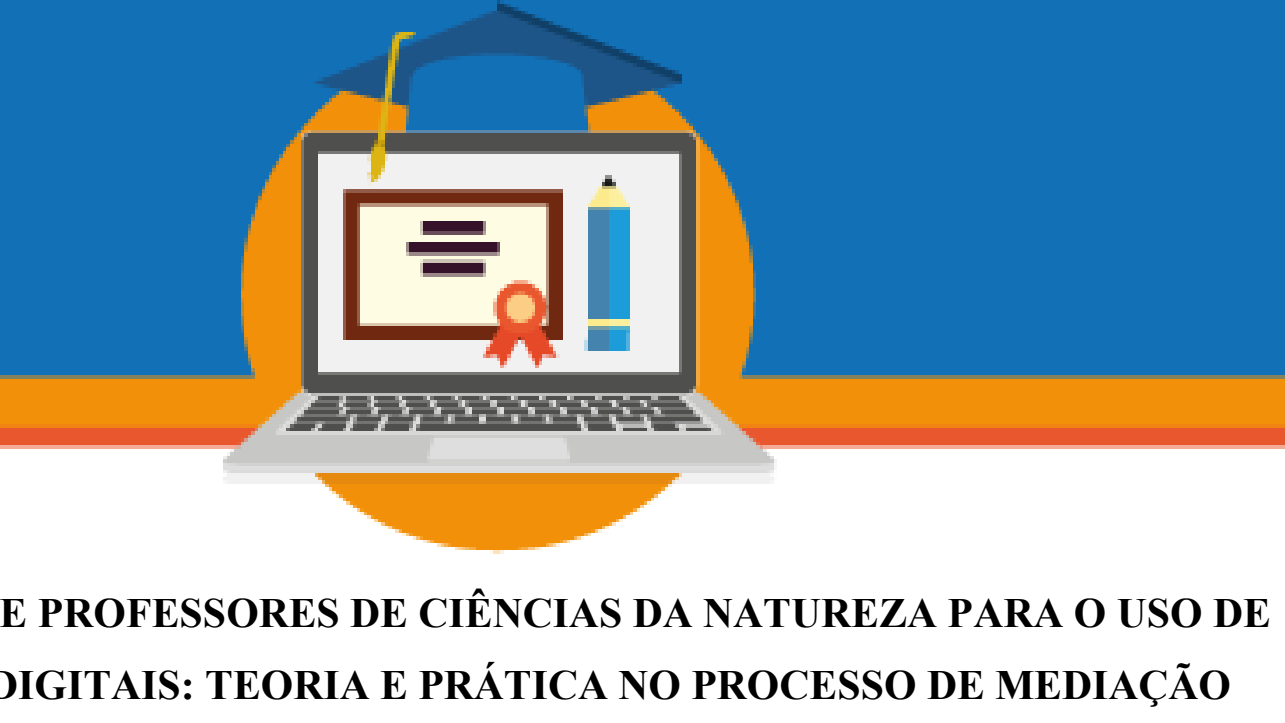

\title{
FORMAÇÃO DE PROFESSORES DE CIÊNCIAS DA NATUREZA PARA O USO DE APARATOS DIGITAIS: TEORIA E PRÁTICA NO PROCESSO DE MEDIAÇÃo
}

\author{
Jhonny David Echalar \\ Doutorando no Programa de Pós-Graduação (PPG) em Educação da Universidade Federal de Goiás (UFG) / \\ Professor efetivo da Secretaria de Estado de Educação, Cultura e Esporte de Goiás \\ ihonnyechalar@gmail.com \\ Wellington Pereira de Queirós \\ Docente no PPG em Ensino de Ciências da Universidade Federal do Mato Grosso do Sul \\ wellington_fis@yahoo.com.br \\ Adda Daniela Lima Figueiredo Echalar \\ Docente no PPG em Educação em Ciências e Matemática UFG \\ addadani@gmail.com
}

\begin{abstract}
Resumo: Este trabalho buscou analisar quais a relação teoria e prática presente em publicações acadêmicas sobre a formação de professores de Ciências da Natureza para o uso de tecnologias. Os dados foram obtidos a partir de um levantamento bibliográfico entre 2006 e 2016, em periódicos da área de Ensino de Ciências com análise de seus conteúdos, sendo possível a construção de categorias de análise. Foram identificados sete artigos que foram analisados em três categorias: teoria, prática e "teoria-prática". Percebemos que o uso de tecnologias aparece no contexto de processos formativos centrados no praticismo de um curso e não como um constructo social.
\end{abstract}

Palavras-chave: Biologia, Física, Ensino.

\section{INTRODUÇÃO}

As informações presentes neste trabalho são um recorte da dissertação de mestrado intitulada "Proposição formativa de professores a partir da reflexão crítica de objetos virtuais de aprendizagem". A pesquisa e reflexões aqui apresentadas fundamentam e justificam a proposta de estudo presente na referida dissertação. Iniciamos discorrendo acerca das alterações na sociedade devido ao desenvolvimento e popularização das diferentes tecnologias digitais, 
abordamos a questão da mediação em processos formativos e, logo em seguida, apresentamos os resultados do levantamento bibliográfico e análises realizadas.

Concordamos que sociedade passa por mudanças cada vez mais rápidas, tanto que para alguns autores estamos, desde os anos 1990, vivenciando a alteração da sociedade industrial para a chamada "sociedade da informação". Com o surgimento da Tecnologia de Informação (TI), das Tecnologias de Informação e Comunicação (TIC) atualmente também designada como Tecnologias Digitais de Informação e Conhecimento (TDIC) devido ao desenvolvimento de novas ferramentas digitais, a indústria passa a desenvolver novas atividades na área de produção de bens e serviços, onde tudo que se transforma em informação passar a ser uma mercadoria com lucratividade e importância estratégica. (BENAKOUCHE, 1985; FERNANDES e ALVES, 1992). Observando este movimento e oportunidade de negócios, empresas passaram a olhar a produção de TDIC para o setor educacional, utilizando-a como mais um recurso operacional de mercado, como a produção de equipamentos e a confecção de softwares. (TAPSCOTT e CASTON, 1995; BRITO, ANTONIALLI e SANTOS, 1997).

Segundo Jucá (2006), a educação sempre dispôs de recursos tecnológicos para serem utilizados pelos educadores como instrumentos mediadores (de informação, de relações, de contexto, de culturas, etc) no processo de ensino-aprendizagem, tais como livros, lousas, modelos, videocassete, televisão e, mais recentemente o computador, os tablets e smartfones estão incluídos nesta lista.

Neste sentido, a utilização de periféricos juntamente com a introdução das TDIC como recurso didático nas instituições de ensino apresenta-se como um desafio para os educadores do século XXI. Sites localizados na internet são uma das fontes mais utilizadas nos ambientes educacionais e fora deles, para realização de pesquisas a pedido dos docentes e que podem ser acessados através de diferentes aparelhos dotados de internet móvel. Essas alterações no cotidiano, pode resultar na mudança cultural sobre o conceito de docente, de uma concepção de "transmissor de informação" e "detentor do conhecimento", para compreendê-lo como mediador entre a informação, o instrumento, o aluno e si próprio (ALLIPRANDINI et al., 2010; SILVA, 2005). 


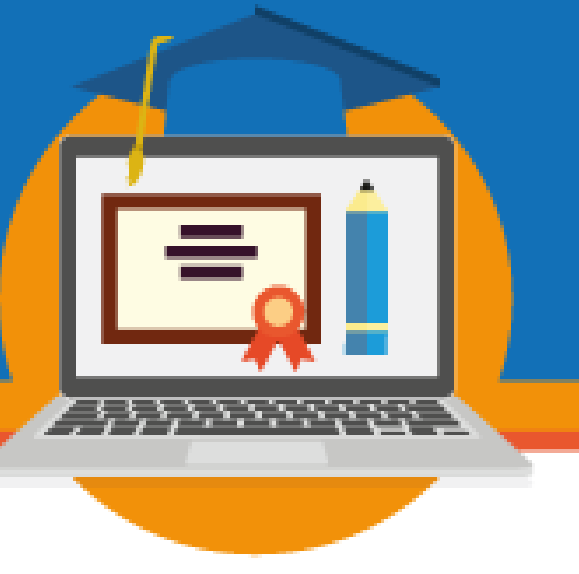

A internet pode oferecer diferentes formas de representação de conteúdo e as escolas têm acesso a novas formas de exposição de informação, visto que diversos meios de comunicação geram múltiplos olhares destes conteúdos por meio de textos, imagens e sons através das TDIC. E por meio destas podem ser possibilitadas novas perspectivas de acesso ao conhecimento, expandindo o espaço da sala de aula a ambientes mais diversificados e atualizados, podendo alterar estratégias (de ensino e aprendizagem) e do comprometimento de alunos e professores com estes processos (AMORIM, 2003; PEREIRA e CORDENONSI, 2009).

\section{A RELAÇÃO TECNOLOGIA/EDUCAÇÃO ENQUANTO ATIVIDADE MEDIADA}

A mediação, é um termo que pode ser encontrado em diversas áreas, como no campo jurídico, na Ciência da Informação, Psicologia, Bioquímica, Teologia e Religiosidade, Arte, Educação e diversas outras (CONSANI, 2008), enquanto uma categoria da dialética, representa o movimento entre a objetivação e subjetivação do sujeito. Segundo Gómez (1997), as diferentes tecnologias, com suas diferentes linguagens e estratégias de comunicação são aparatos que oportunizam a mediação na recepção das mensagens, influenciando no processo de percepção e interação com a informação, sendo deste modo fundamental buscar compreendê-la nos processos de formação, tanto de alunos quanto de professores, que utilizem de tecnologias neste processo.

Neste sentido, a mediação é compreendida não apenas como uma explicação objetiva da relação entre tecnologia e educação, mas como um processo, como relações que se deslocam constantemente devido alterações culturais, históricas, sociais, etc, retirando deste modo a concepção de que mediação seria algo que está inserido entre dois elementos distintos (MOLON, 2000). Nesta perspectiva ao analisarmos momentos formativos estamos buscando compreender como se apresenta este processo e quais elementos conceituais os permeiam, neste caso, a linguagem, a tecnologia, o aluno, o professor o momento. 
Peixoto e Araújo (2012) apresentam duas abordagens comumente presente em estudos sobre o uso das tecnologias na educação: tecnocentrismo ${ }^{1}$ e antropocentrismo ${ }^{2}$. Na primeira, a tecnologia é tida como um elemento que determina a configuração social e cultural. Ela seria considerada quase como um sistema autônomo dotado de lógica própria em seu desenvolvimento capaz de influenciar o contexto ao qual se insere. Na segunda abordagem ocorre a incorporação das TDIC, como sendo recursos didático-pedagógicos moldados pelos sujeitos. Nesta concepção se compreende que nas relações tecnologia/educação exista neutralidade nos objetos técnicos, ou seja, a responsabilidade é direcionada para o uso que os sujeitos fazem dos instrumentos que lhe são disponibilizados.

Uma terceira abordagem é denominada de sociotécnica. Esta, entende que as tecnologias obviamente possuem algumas funcionalidades instrumentais que são transferidas aos usos que são feitos delas, mas que estas funcionalidades não são os únicos elementos que determinam estes usos. Sob uma concepção sociotécnica se compreende que tanto o contexto (político, econômico, cultural, histórico, etc), quanto as intencionalidades dos sujeitos são elementos de interferência na utilização dos instrumentos (PEIXOTO, 2012).

Essa abordagem nos possibilita compreender que as tecnologias são fruto do trabalho humano em seus diferentes âmbitos e que tanto este, quanto as ações humanas, não estão libertos no que tange ao contexto sócio-histórico no qual são desenvolvidos. $\mathrm{O}$ uso de tecnologia na educação pode atender a diferentes abordagens pedagógicas e de educação, tanto na utilização, quanto na criação destes recursos. Assim, compreendermos as diversas concepções pedagógicas que estão presentes nos mais variados âmbitos educacionais, desde os materiais desenvolvidos até os processos de formação, tanto a inicial quanto a continuada é fundamental, pois permite ao docente fazer escolhas intencionais a sua atividade profissional. Libâneo (2003, p. 2) nos acrescenta que:

\footnotetext{
${ }^{1}$ A perspectiva tecnocêntrica toma a tecnologia como elemento central de explicação das relações entre as tecnologias e a educação. Nesta perspectiva, não são os professores e alunos, mas a solução técnica que é considerada mais eficaz para melhorar a produtividade e a qualidade das ações realizadas.

${ }^{2}$ Esta concepção trata a relação entre tecnologia e educação pelo viés da abordagem instrumental. A técnica é deslocada para a margem, sendo os professores e os alunos colocados no núcleo central das ações humanas mediadas pelas tecnologias.
} 


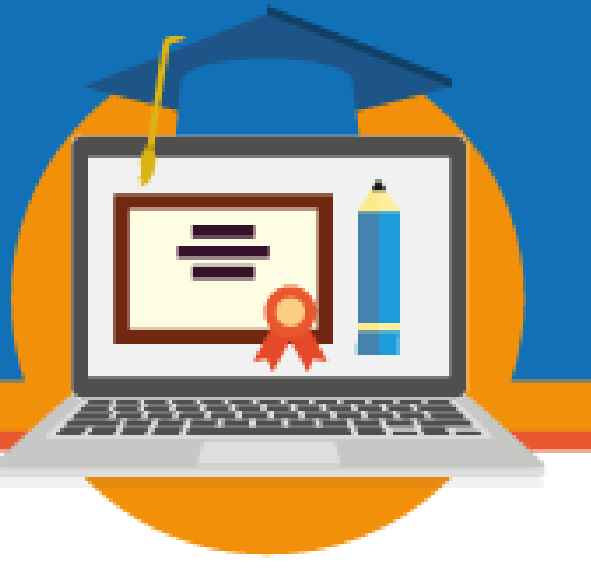

Uma boa parte dos professores, provavelmente a maioria, baseia sua prática em prescrições pedagógicas que viraram senso comum, incorporadas quando de sua passagem pela escola ou transmitidas pelos colegas mais velhos; entretanto, essa prática contém pressupostos teóricos implícitos.

De tal modo que as tendências sobre as concepções pedagógicas se encontram, explícita ou implicitamente, inseridas em práticas e materiais desenvolvidos em quaisquer âmbitos educacionais, cabendo a quem for utilizar, identificá-las. Ou seja, as diversas concepções pedagógicas permitem que as tecnologias digitais possam ser utilizadas a partir de suas prerrogativas devido as suas maleabilidade e flexibilidade, justamente pelo trabalho docente não é inteiramente passivo diante das TDIC, sendo permeado de intencionalidade e seguindo determinadas orientações didático-pedagógicas que podem ser objeto de sua escolha (SANCHO, 2006).

Pelo exposto se observa que são diversas as possibilidades de pesquisa quanto a relação entre educação e tecnologia. Neste contexto, objetivamos observar: como as pesquisas acadêmicas apresentam a mediação entre a teoria e a prática nos processos de formação de professores da área de Ciências da Natureza associados ao uso de aparatos digitais?

Foi realizada uma pesquisa bibliográfica tendo como parâmetro de busca publicações que discorressem da formação de professores associada ao uso de aparatos digitais. Buscou-se artigos publicados entre os anos de 2006 e 2016, sendo selecionados, para o desenvolvimento deste estudo, nove periódicos da área de ensino: Alexandria, Caderno Brasileiro de Ensino de Física, Revista Brasileira de Ensino de Física, Experiências em Ensino de Ciências, Investigações em Ensino de Ciências, Revista Brasileira de Pesquisa e Educação em Ciência, Revista Ciência e Ensino, Revista Eletrônica de la Enseñaza de la Ciência, revista Ciência e Educação e Ensaio: Pesquisa em Educação em Ciências. A escolha destes periódicos foi feita por terem grande relevância no meio acadêmico e na divulgação científica na área de ensino de Ciências. 


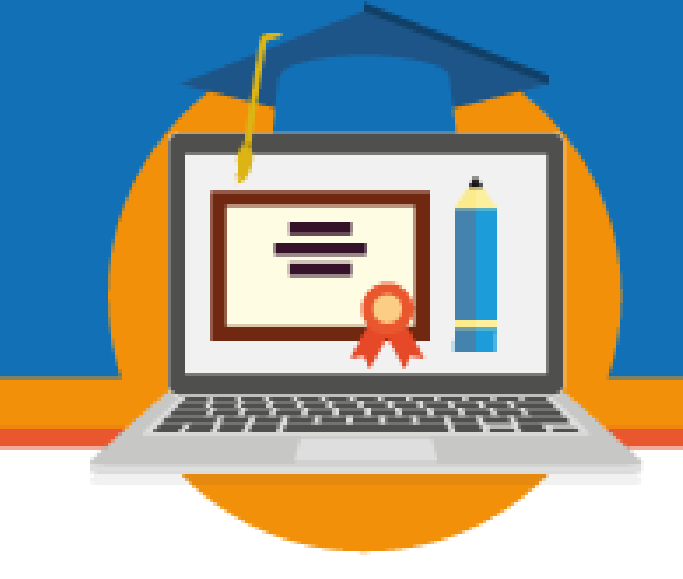

\section{AS FORMAÇÕES E OS USOS DE TECNOLOGIAS NO ENSINO DE CIÊNCIAS}

Foram encontradas sete publicações que contemplavam o objetivo desta pesquisa bibliográfica (Quadro 1). A maior parte das publicações desenvolveu seu trabalho com professores em formação continuada, totalizando cinco artigos, de modo que os trabalhos com professores em formação inicial foram observados, apenas em duas publicações.

Quadro 1 - Publicações encontradas na revisão bibliográfica.

\begin{tabular}{|c|c|}
\hline TÍTULO & AUTORES \\
\hline $\begin{array}{l}\text { Os formadores de professores e o desafio em potencializar o ensino de } \\
\text { conhecimentos químicos com a incorporação dos dispositivos móveis. } \\
\text { Investigações em Ensino de Ciências. v. 19, n. 1, p. 77-89, } 2014 \text {. }\end{array}$ & $\begin{array}{l}\text { JACON, L. S. C.; } \\
\text { OLIVEIRA, A. C. G.; } \\
\text { MARTINES, E. A. L. M.; } \\
\text { MELLO, I. C. }\end{array}$ \\
\hline $\begin{array}{l}\text { Investigando a aprendizagem de professores de Física acerca do fenômeno } \\
\text { da interferência quântica. Ciência \& Educação. v. 14, n. 1, p. 35-54, } 2008 .\end{array}$ & $\begin{array}{l}\text { OSTERMANN, F.; } \\
\text { PRADO, S. D.; RICCI, T. } \\
\text { S. F. }\end{array}$ \\
\hline $\begin{array}{l}\text { A formação inicial do professor na modalidade a distância para o uso das } \\
\text { tecnologias digitais no ensino de Matemática: o caso de uma disciplina de } \\
\text { prática de ensino. ALEXANDRIA - Revista de Educação em Ciência e } \\
\text { Tecnologia. v. } 8 \text {, n. 3, p. } 113-130 \text {, nov. } 2015 \text {. }\end{array}$ & $\begin{array}{l}\text { ZABEL, M.; } \\
\text { MALHEIROS, A. P. S. }\end{array}$ \\
\hline $\begin{array}{l}\text { Formação continuada de professores de Química: uma proposta envolvendo } \\
\text { a inserção da informática nas práticas de sala de aula. Revista Brasileira } \\
\text { de Pesquisa em Educação em Ciências. v. 9, n. 2, p. 1-17, } 2009 .\end{array}$ & $\begin{array}{l}\text { GABINI, W. S.; DINIZ, R. } \\
\text { E. S. }\end{array}$ \\
\hline $\begin{array}{l}\text { Divulgação científica na formação docente: construindo e divulgando } \\
\text { conhecimento por meio do rádio e da internet. Experiências em Ensino de } \\
\text { Ciências. v. } 8 \text {, n. } 2 \text {, p. } 80-94,2013 \text {. }\end{array}$ & $\begin{array}{l}\text { RODRIGUES, A. A; } \\
\text { DAMASIO, F.; SOUZA, } \\
\text { S. L. }\end{array}$ \\
\hline $\begin{array}{l}\text { A presença da tecnologia na educação matemática: efetuando uma tessitura } \\
\text { com situações/cenas1 do filme Avatar e vivências em um curso a distância } \\
\text { de formação de professores. Alexandria - Revista de Educação em } \\
\text { Ciência e Tecnologia. Florianópolis, v. 6, n. 1, p.61-103, abr. } 2013 \text {. }\end{array}$ & $\begin{array}{l}\text { BICUDO, M. A. V.; } \\
\text { ROSA, M. }\end{array}$ \\
\hline $\begin{array}{l}\text { O uso de softwares na prática profissional do professor de matemática. } \\
\text { Ciência \& Educação. v. } 18, \text { n. } 3, \text { p. } 527-542,2012 .\end{array}$ & $\begin{array}{l}\text { SANT'ANA, C. C.; } \\
\text { AMARAL, R. B.; } \\
\text { BORBA, M. C. }\end{array}$ \\
\hline
\end{tabular}

Fonte: elaborado pelos autores. 
Esse resultado pode indicar que a formação inicial de professores é um campo que possibilita o desenvolvimento de projetos de pesquisa que integrem recursos educacionais digitais, com uma fundamentação teórica sólida para além da capacitação técnica focada no simples uso e aplicação destes recursos. O mesmo podemos afirmar acerca da formação continuada, pois compreendemos que para o período analisado são poucas as publicações encontradas sob a perspectiva formativa já comentada.

Todas as publicações encontradas foram analisadas por meio da análise de conteúdo (BARDIN, 1977), cujo objetivo era compreender a concepção de formação de professores associada ao uso de ferramentas digitais. Após a análise foi possível a identificação de três categorias: teoria, prática e "teoria e prática" (Tabela 2). Devido à especificidade dos trabalhos, foram criadas e distribuídas entre estas categorias, seis unidades de análise.

Tabela 2 - Apresentação das categorias de análise e suas respectivas unidades.

\begin{tabular}{|c|l|c|c|}
\hline \multirow{2}{*}{ CATEGORIA } & \multicolumn{1}{|c|}{ UNIDADE } & $\begin{array}{c}\text { ARTIG } \\
\text { O }\end{array}$ & ANO \\
\hline \multirow{3}{*}{ Teoria e prática } & Formação teórica e instrumentalização de professores & $\begin{array}{r}\text { TP-1 } \\
\text { TP-2 }\end{array}$ & $\begin{array}{c}\text { An } \\
2009\end{array}$ \\
\cline { 2 - 4 } & Formação teórica interdisciplinar e produção material & TP-3 & 2013 \\
\hline \multirow{3}{*}{ Prática } & Análise de projeto já consolidado & PR-1 & 2012 \\
\cline { 2 - 4 } & Instrumentalização para mudança conceitual & PR-2 & 2008 \\
\cline { 2 - 5 } & $\begin{array}{l}\text { Criação e aplicação de ferramenta de suporte ao } \\
\text { ensino }\end{array}$ & PR-3 & 2014 \\
\hline \multirow{2}{*}{ Teoria } & $\begin{array}{l}\text { Comparação entre contextos reais e elementos de } \\
\text { ficção }\end{array}$ & TE-1 & 2013 \\
\hline
\end{tabular}

Fonte: elaborado pelos autores.

A categoria de análise "teoria e prática" agrupa os trabalhos que, em seu desenvolvimento, de algum modo abordaram tanto a formação teórica quanto a realização de práticas. Nesta categoria estão presentes três publicações organizadas em duas unidades de análise, mas apenas uma unidade possibilitou o agrupamento de dois trabalhos, denominada de formação teórica e instrumentalização de professores.

Nos trabalhos desta unidade, observou-se que o percurso formativo possui dois momentos distintos. Em um primeiro momento, houve discussão teórica acerca da inserção da tecnologia 
na educação e a instrumentalização dos professores para uso de ferramentas e softwares em um segundo momento. Esta categoria se aproxima de um processo de mediação permeado pela abordagem sociotécnica, sendo constituída de elementos que buscaram associar fatores contextuais, neste caso fundamentação teórica, com desenvolvimento de aprendizagem técnica.

Em um dos trabalhos, Zabel e Malheiros (2015) discutem de que modo uma disciplina de Prática de Ensino contribui para a formação do professor de Matemática em relação ao uso das tecnologias digitais na educação básica. A disciplina foi dividida em dois momentos, no primeiro foram realizadas discussões acerca de temas relacionados com Educação Matemática, tecnologias e o uso de tecnologias no ensino de Matemática. No segundo momento, os professores em formação tiveram de aprender a utilizar softwares para construção de podcasts e screencasts, com foco na produção de material didático.

Outro trabalho inserido, nesta unidade, foi desenvolvido por Gabini e Diniz (2009) aborda a formação continuada de professores de Química associada ao uso do computador, como instrumento pedagógico em sala de aula. Segundo os autores, o processo formativo fundamentou-se na racionalidade prática, da reflexão crítica e a publicação, um recorte de resultados da pesquisa de doutorado do autor principal. As atividades envolveram a exploração dialogada de softwares; dois deles disponíveis na Sala Ambiente de Informática das escolas estaduais que integram a pesquisa e outros presentes no mercado, além de softwares livres.

A outra unidade desta categoria de análise foi nomeada de formação teórica interdisciplinar e produção de material e assim como nas demais unidades, apenas um trabalho fez se presente. Dois elementos que distinguem esta categoria é a realização de uma formação teórica, permeada pelo trabalho interdisciplinar e por ter produzido material de divulgação científica pelos alunos em formação. Neste trabalho Rodrigues, Damasio e Souza (2013), implementaram um projeto de ensino, referenciado na Teoria da Aprendizagem Significativa e no Sócio-Interacionismo, em uma turma do curso de licenciatura em Ciências da Natureza, em que os estudantes participaram de um programa de produção de inserções radiofônicas e construção de um blog sobre radioatividade e energia nuclear, apoiada por três unidades 
curriculares diferentes: Princípios da Ciência II, Português II e Epistemologia e História das Ciências.

Nos textos, "O uso de softwares na prática profissional do professor de matemática" (PR1), "Investigando a aprendizagem de professores de Física acerca do fenômeno da interferência quântica" (PR-2) e "Os formadores de professores e o desafio em potencializar o ensino de conhecimentos químicos com a incorporação dos dispositivos móveis” (PR-3), é possível observar que o elemento "ação" é o eixo central de seu desenvolvimento e devido a esta característica foram agrupados na categoria denominada "prática". A seguir, apresentamos as unidades de análise desta categoria e as publicações encontradas para cada uma destas unidades.

A unidade denominada análise de projeto já consolidado efetivou-se pelo fato de ter pesquisado os resultados de um curso de formação continuada de professores a distância, que buscava familiarizar professores da educação básica a dois softwares, destinados ao ensino de matemática: o Geometricks e o Winplot. O objetivo principal da pesquisa, realizada por Sant'Ana, Amaral e Borba (2012) foi identificar "se, e como" os professores que concluíram o curso incorporaram estas ferramentas à sua prática profissional. Compreendemos que o foco foi justamente na prática que os docentes formados estão desenvolvendo, o que justifica sua inclusão nas referidas categoria e unidade de análise.

O trabalho desenvolvido por Ostermann, Prado e Ricci (2008) analisa a evolução conceitual de 14 professores de ensino médio que foram estudantes, no $2^{\circ}$ semestre de 2005 , de uma disciplina sobre Física Quântica (FQ) no Mestrado Profissional em Ensino de Física da Universidade Federal do Rio Grande do Sul (UFRGS). Objetivando a aquisição ou mudança de conceitos da área específica de Física a formação centrou-se na utilização de roteiros de aula, a utilização de um software livre do tipo "bancada virtual", que simula o fenômeno da interferência quântica e questionários teóricos. Há a inserção de parâmetros no simulador e os alunos deveriam realizar comparações e relatar o que estavam observando. A partir destes elementos a unidade de análise "instrumentalização para mudança conceitual" se faz necessária já que que não houve reflexões para além da formação técnica e conteudista. 
A unidade denominada "criação e aplicação de ferramenta de suporte ao ensino" apresenta como elemento fundamental a criação por pesquisadores (JACON et al., 2014) de uma ferramenta destinada ao suporte ao ensino e somente após sua finalização o mesmo é aplicado a alunos de licenciatura. O objetivo de sua aplicação é de analisar a funcionalidade do recurso criado, não havendo outras discussões ou, até mesmo, possibilidade dos "analistas" sugerirem alterações ou planejamento de uso pedagógico da ferramenta.

As autoras citadas anteriormente buscaram promover o desenvolvimento profissional de formadores de professores na área de Ciências Químicas e Informática. As mesmas elaboraram um estudo dirigido para ser utilizado em dispositivos móveis, junto aos professores, em formação inicial do curso de licenciatura em Química. Segundo as pesquisadoras, a pesquisa apresentou que a aprendizagem com mobilidade aumenta o interesse, a motivação e, principalmente, a curiosidade dos acadêmicos em aprender de uma maneira diferente, mas as limitações técnicas e sociais dos acadêmicos ainda são um grande problema a ser resolvido.

Sobre estas unidades o que se observa que há uma abordagem mais relacionada com elementos de uma concepção determinista em relação ao uso de tecnologias, não inserindo elementos questionadores ou permitindo que os sujeitos em formações tivessem maior protagonismo. A nosso ver o processo de mediação neste cenário, não contribui de forma significativa para se romper com o status quo presente em âmbito social no que tange as desigualdades de formação política, histórica, acadêmica e econômica

A categoria de análise denominada "teoria" foi criada por termos encontrado um trabalho, cujo foco era a discussão teórica dos elementos obtidos, a partir de um curso de formação continuada de professores, associados a situações de um filme de ficção científica. Da leitura deste material, elaborou-se a unidade de análise denominada "comparação entre contextos reais e elementos de ficção".

Inserido nesta unidade, o trabalho desenvolvido por Bicudo e Rosa (2013) teve como objetivo expor os modos de o ser humano ser com a tecnologia. Para isto, realizaram aproximações entre situações projetadas em um filme de ficção científica e situações em que se realiza Educação Matemática com a presença da tecnologia. Os autores afirmam, buscando 


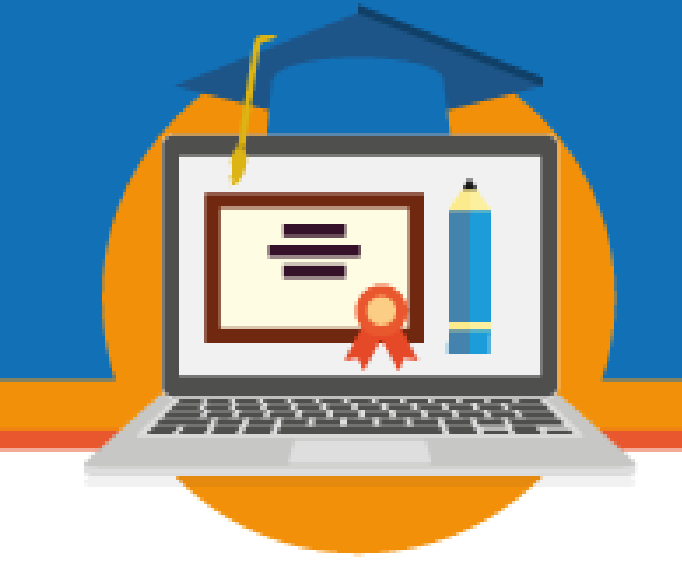

dados no chat de um curso à distância de formação de professores de Matemática, que há confluência de concepções e interconexões presentes entre o visto na ficção e o que já está sendo vislumbrado/produzido em termos educacionais. Segundo os mesmos, a informática presentifica-se no processo cognitivo, nos termos ser-com, pensar-com e saber-fazer-com-ociberespaço, deixando de ser apenas um mero instrumento.

Durante a realização do referido curso, os pesquisadores obtiveram dados para posterior análise, como discurso de professores, situações de convívio, resolução de atividades e diálogos em chats. Estes dados, então, são relacionados e comparados com elementos presentes em um filme de ficção científica, de modo a evidenciar que situações similares podem ser observadas nos dois campos, no real e no ficcional, no que tange a inserção da tecnologia nas relações sociais.

\section{CONSIDERAÇÕES FINAIS}

Ao retomarmos o problema de pesquisa que norteia este texto - como as pesquisas acadêmicas apresentam a mediação entre a teoria e a prática nos processos de formação de professores da área de Ciências da Natureza associados ao uso de aparatos digitais? Observamos que os trabalhos desenvolvidos em muito se aproximaram de modelos de formação pautados na reflexão da prática. Visto que dão maior centralidade na discussão e nos resultados ao processo de prática, desconectado a princípios teóricos de uma teoria pedagógica.

Nosso entendimento é de que um processo formativo seguindo esta linha epistemológica pode incidir em uma prática guiada pelo determinismo tecnológico inserido na abordagem tecnocêntrica, popularizando a concepção de estarmos em uma "era tecnológica" superior as demais e que retira as marcas sociais e históricas dos objetos técnicos, tornando-os inevitáveis e inquestionáveis.

Assim o processo de mediação estaria permeado por elementos que resultariam em uma formação alienante e os sujeitos podem não ter a percepção de que os objetos são uma construção humana, que contribuem para com as dinâmicas sociais, culturais e históricas, podendo serem utilizados inclusive como meio de exploração entre diferentes classes sociais. 


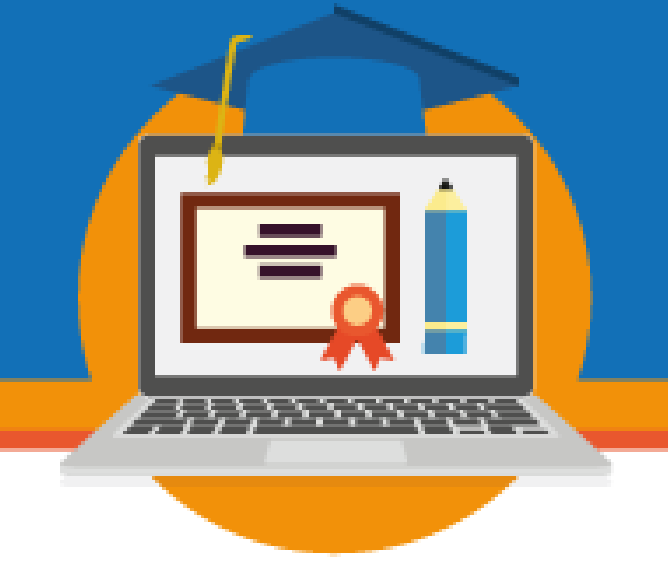

Os dados e análises nos possibilitam vislumbrar o seguinte cenário: há a necessidade projetos de formação de professores que sejam pautados por uma fundamentação pedagógica e que as associem ao uso ou a produção de recursos tecnológicos digitais, para além de uma instrumentalização prática.

Outro ponto importante é que não encontramos nenhum trabalho desenvolvido sob os preceitos de orientações didático-pedagógicas ou de formação de professores, com proximidade teórica que vislumbrem a alteração das contradições e desigualdades do status quo presente na sociedade capitalista.

\section{REFERÊNCIAS}

ALLIPRANDINI, P. M. Z.; STRAUB, S. L. W.; BRUGNERA, E. D. ; OLIVEIRA, T.P. . O processo de memória em jovens: o efeito do uso do computador. Ciências \& Cognição (UFRJ), v. 15, p. 21-30, 2010.

AMORIM, J. S.; BARANAUSKAS, M. C.; MELO, A. M.; ALCOBA, S. A. C. Desafios para a Tecnologia da Informação e Comunicação em Espaço Educacional Inclusivo. In: XXV CONGRESSO DA SOCIEDADE BRASILEIRA DE COMUNICAÇÃO, 2005, São Paulo. XI Workshop Sobre Informática na Escola. Anais... São Paulo: São Leopoldo, 2005.

BARDIN, L. Análise de conteúdo. Lisboa, Edições 70, 1977.

BENAKOUCHE, R. (Org.). A questão da informática no Brasil. São Paulo: Editora Brasiliense e CNPq, 1985.

BICUDO, M. A. V.; ROSA, M. A presença da tecnologia na educação matemática: efetuando uma tessitura com situações/cenas 1 do filme Avatar e vivências em um curso a distância de formação de professores. Alexandria - Revista de Educação em Ciência e Tecnologia. Florianópolis, v. 6, n. 1, p.61-103, abr. 2013.

BRITO, M. J.; ANTONIALLI, L. M.; SANTOS, A. C. Tecnologia da informação e processo produtivo de gestão em uma organização cooperativa: um enfoque estratégico. Revista de Administração Contemporânea, v. 1, n. 1, p. 77-95, jan./abr. 1997

CONSANI, M. A. Mediação tecnológica na educação: conceitos e aplicações. Tese (Doutorado em Comunicações e Artes), Universidade de São Paulo, São Paulo. 2008. 
FERNANDES, A. A.; ALVES, M. M. Gerência estratégica da tecnologia da informação: obtendo vantagens competitivas. Rio de Janeiro: LTC, 1992

GABINI, W. S.; DINIZ, R. E. S. Formação continuada de professores de Química: uma proposta envolvendo a inserção da informática nas práticas de sala de aula. Revista Brasileira de Pesquisa em Educação em Ciências. v. 9, n. 2, p. 1-17, 2009.

GOMEZ, G. O. Professores e meios de comunicação: desafios, estereótipos. Comunicação \& Educação, São Paulo, n. 10, p. 57-68, dec. 1997. ISSN 2316-9125. Disponível em: $<$ http://www.revistas.usp.br/comueduc/article/view/36323>. Acesso em: 10 fev. 2018.

JACON, L. S. C.; OliveIRA, A. C. G.; MARTINES, E. A. L. M.; MELlO, I. C. Os formadores de professores e o desafio em potencializar o ensino de conhecimentos químicos com a incorporação dos dispositivos móveis. Investigações em Ensino de Ciências. v. 19, n. 1, p. 77-89, 2014.

JUCÁ, C. S. S. A relevância dos softwares educativos na educação profissional. Ciênc. cogn., Rio de Janeiro , v. 8, p. 22-28, ago. 2006.

LIBÂNEO, J. C. Democratização da escola pública: a pedagogia crítico-social dos conteúdos.19. ed. São Paulo: Loyola, 2003, 160 p.

MOLON, S. I. Subjetividade e constituição do sujeito em Vygotsky. In: CONFERÊNCIA DE PESQUISA SÓCIO-CUlTURAL, 3., 2000, Campinas. Anais... Campinas: 2000, p. 1-19. Disponível em: <http://www.fae.unicamp.br/br2000/>. Acesso em: 26 jan. 2018.

OSTERMANN, F.; PRADO, S. D.; RICCI, T. S. F. Investigando a aprendizagem de professores de Física acerca do fenômeno da interferência quântica. Ciência \& Educação. v. 14, n. 1, p. 35-54, 2008.

PEIXOTO, J. Tecnologia e mediação pedagógica: perspectivas investigativas. In: KASSAR, M. de C. M.; SILVA, F. de C. T. (Org.). Educação e pesquisa no Centro-Oeste: políticas públicas e formação humana. 1ed.Campo Grande: Editora da UFMS, 2012, v. 1, p. 283-294.

PEIXOTO, J.; ARAUJO, C. H. dos S. Tecnologia e educação: algumas considerações sobre o discurso pedagógico contemporâneo. Educação \& Sociedade, Campinas, v. 33, n. 118, p. 253 268, mar., 2012.

PEREIRA, L. L.; CORDENONSI, A. Z. Softwares educativos: Uma Proposta de Recurso Pedagógico para o Trabalho de Reforço das Habilidades de Leitura e Escrita com Alunos dos Anos Iniciais. Revista Novas Tecnologias na Educação. Rio Grande do Sul, v.7, n.3, dezembro/2009. p. 1-13.

RODRIGUES, A. A; DAMASIO, F.; SOUZA, S. L. Divulgação científica na formação docente: construindo e divulgando conhecimento por meio do rádio e da internet. Experiências em Ensino de Ciências. v. 8, n. 2, p. 80-94, 2013. 


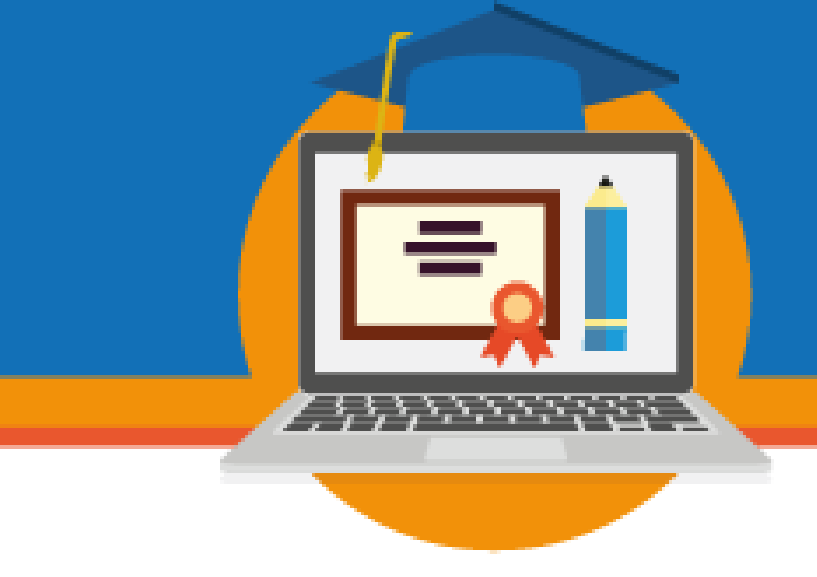

SANCHO, J. M. De tecnologias da informação e comunicação a recursos educativos. In: SANCHO, J. M; HERNÁNDEZ, F. Tecnologias para transformar a educação. Porto Alegre: Artmed, 2006. p. 15-42.

SANT'ANA, C. C.; AMARAL, R. B.; BORBA, M. C. O uso de softwares na prática profissional do professor de matemática. Ciência \& Educação. v. 18, n. 3, p. 527-542, 2012.

SILVA, E. T. Revalorização do livro diante das novas mídias. Veículos e linguagens do mundo contemporâneo: a educação do leitor para as encruzilhadas da mídia. 50 p. 2005. Disponível em: <http://portal.mec.gov.br/seed/arquivos/pdf/1sf.pdf>. Acesso em: 10 fev 2018. TAPSCOTT, D.; CASTON, A. Mudança de paradigma: a nova promessa da tecnologia da informação. São Paulo: MakronMcGraw-Hill, 1995.

ZABEL, M.; MALHEIROS, A. P. S. A formação inicial do professor na modalidade a distância para o uso das tecnologias digitais no ensino de Matemática: o caso de uma disciplina de prática de ensino. ALEXANDRIA - Revista de Educação em Ciência e Tecnologia. v. 8, n. 3, p. 113-130, nov. 2015. 